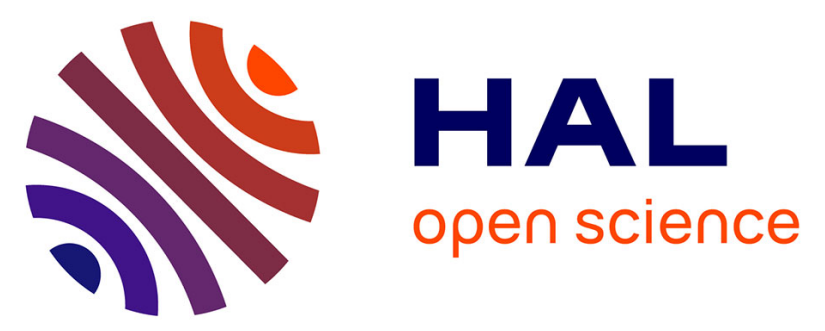

\title{
Control of the Evolution of Iron Peroxide Intermediate in Superoxide Reductase from Desulfoarculus baarsii. Involvement of Lysine 48 in Protonation
}

Florence Bonnot, Thibaut Molle, Stéphane Ménage, Yohann Moreau, Simon Duval, Vincent Favaudon, Chantal Houée-Levin, Vincent Nivière

\section{To cite this version:}

Florence Bonnot, Thibaut Molle, Stéphane Ménage, Yohann Moreau, Simon Duval, et al.. Control of the Evolution of Iron Peroxide Intermediate in Superoxide Reductase from Desulfoarculus baarsii. Involvement of Lysine 48 in Protonation. Journal of the American Chemical Society, 2012, 134 (11), pp.5120-30. 10.1021/ja209297n . hal-01075283

\section{HAL Id: hal-01075283 \\ https://hal.science/hal-01075283}

Submitted on 7 Jan 2015

HAL is a multi-disciplinary open access archive for the deposit and dissemination of scientific research documents, whether they are published or not. The documents may come from teaching and research institutions in France or abroad, or from public or private research centers.
L'archive ouverte pluridisciplinaire HAL, est destinée au dépôt et à la diffusion de documents scientifiques de niveau recherche, publiés ou non, émanant des établissements d'enseignement et de recherche français ou étrangers, des laboratoires publics ou privés. 


\title{
Control of the evolution of iron peroxide intermediate in superoxide reductase from Desulfoarculus baarsii. Involvement of lysine 48 in protonation
}

\author{
Florence Bonnot $^{1,2,3}$, Thibaut Molle $e^{1,2,3}$, Stéphane Ménage ${ }^{1,2,3}$, Yohann Moreau ${ }^{1,2,3}$, Simon Duval ${ }^{1,2,3}$, \\ Vincent Favaudon ${ }^{4}$, Chantal Houée-Levin ${ }^{5}$, and Vincent Nivière ${ }^{1,2,3}$ \\ ${ }^{1}$ CEA, iRTSV, Laboratoire de Chimie et Biologie des Métaux, F-38054 Grenoble, France. \\ ${ }^{2}$ Université de Grenoble, F-38000 Grenoble, France. \\ ${ }^{3}$ CNRS, UMR 5249, F-38054 Grenoble, France. \\ ${ }^{4}$ Institut Curie, Inserm U612, Bâtiment 110-112, Centre Universitaire 91405 Orsay Cedex, France. \\ ${ }^{5}$ Laboratoire de Chimie Physique, UMR8000 CNRS/Université Paris-Sud, Bâtiment 350, Centre Universitaire 91405 Orsay \\ Cedex, France. \\ Supporting Information Placeholder
}

\begin{abstract}
Superoxide reductase is a non-heme iron metalloenzyme that detoxifies superoxide anion radicals $\mathrm{O}_{2}{ }^{\bullet-}$ in some microorganisms. Its catalytic mechanism was previously proposed to involve a single ferric iron (hydro)peroxo intermediate, which is protonated to form the reaction product $\mathrm{H}_{2} \mathrm{O}_{2}$. Here we show by pulse radiolysis that the mutation of the well-conserved lysine 48 into isoleucine in the SOR from Desulfovibrio baarsii dramatically affects its reaction with $\mathrm{O}_{2}{ }^{\bullet}$. Although the first reaction intermediate and its decay are not affected by the mutation, $\mathrm{H}_{2} \mathrm{O}_{2}$ is no longer the reaction product. In addition, in contrast to the wildtype SOR, the lysine mutant catalyzes a two-electron oxidation of an olefin into epoxide in the presence of $\mathrm{H}_{2} \mathrm{O}_{2}$, suggesting formation of iron-oxo intermediate species in this mutant. In agreement with the recent X-ray structures of the peroxide intermediates trapped in a SOR crystal, these data support the involvement of lysine 48 in the specific protonation of the proximal oxygen of the peroxide intermediate to generate $\mathrm{H}_{2} \mathrm{O}_{2}$, thus avoiding formation of iron-oxo species, as is observed in cytochrome P450. In addition, we proposed that the first reaction intermediate observed by pulse radiolysis is a ferrous-iron superoxo species, in agreement with TD-DFT calculations of the absorption spectrum of this intermediate. A new reaction scheme for the catalytical mechanism of SOR with $\mathrm{O}_{2}{ }^{\circ-}$ is presented in which ferrous iron-superoxo and ferric hydroperoxide species are reaction intermediates, and the lysine 48 plays a key role in the control of the evolution of iron peroxide intermediate to form $\mathrm{H}_{2} \mathrm{O}_{2}$.
\end{abstract}

\section{INTRODUCTION}

Detoxification of the superoxide anion radical $\mathrm{O}_{2}^{\bullet-}$ is one of the main processes which allows the cells to withstand oxidative stress. ${ }^{1,2}$ Superoxide dismutase (SOD) has long been considered as the sole enzymatic system able to eliminate $\mathrm{O}_{2}{ }^{\bullet}$, by catalyzing its dismutation into $\mathrm{H}_{2} \mathrm{O}_{2}$ and $\mathrm{O}_{2}{ }^{3}$ Recently, however, evidence for the existence of an alternative enzymatic system to detoxify $\mathrm{O}_{2}{ }^{\bullet-}$ was discovered in some specific bacteria. ${ }^{4,5}$ This enzyme, called superoxide reductase (SOR), catalyzes the reduction of $\mathrm{O}_{2}{ }^{\bullet-}$ into $\mathrm{H}_{2} \mathrm{O}_{2}$ without production of $\mathrm{O}_{2}$. $\mathrm{O}_{2}^{\bullet-}+1 \mathrm{e}^{-}+2 \mathrm{H}^{+} \rightarrow \mathrm{H}_{2} \mathrm{O}_{2} \quad(\mathrm{SOR})$

Unlike SOD, SOR requires a source of electrons to reduce $\mathrm{O}_{2}{ }^{\bullet-}$, which can be provided by cellular reductases and/or soluble electron transfer proteins. ${ }^{6-8}$ Although SODs and SORs are structurally unrelated, they are both able to react with $\mathrm{O}_{2}{ }^{--}$at a nearly diffusion-controlled rate and SOR has appeared as efficient as SOD to protect cells from $\mathrm{O}_{2}{ }^{\bullet}$ induced stress. ${ }^{6}$

SORs, also known as desulfoferrodoxin or neelaredoxin, are small iron metalloproteins, which all contain the same active site. ${ }^{9-12}$ It consists of a mononuclear ferrous iron site, in an atypical $\left[\mathrm{FeN}_{4} \mathrm{~S}_{1}\right]$ coordination, where the nitrogen ligands are provided by four histidine residues and the sulfur ligand, in an axial position, by a cysteine residue. ${ }^{13,14}$ A similar $\left[\mathrm{Fe} \mathrm{S}_{1} \mathrm{~N}_{4}\right.$ ] coordination is also present in the active site of cytochrome $\mathrm{P} 450$, with however the presence of a porphyrin ring instead of histidine ligands. ${ }^{15}$ Different classes of SOR have been described, depending on the presence of additional structural domains. ${ }^{9-12}$ The enzyme from Desulfoarculus baarsii presents an additional N-terminal domain which contains a second mononuclear iron center $\left[\mathrm{Fe}^{3+}(\mathrm{Cys}) \mathrm{S}_{4}\right]$, similar to that found in desulforedoxin. ${ }^{5,12,14}$ It was recently proposed that this iron center serves as an electron relay between some peculiar electron donor proteins and the active site.$^{16,17}$

The mechanism of the reduction of $\mathrm{O}_{2}{ }^{\bullet-}$ by SOR has been extensively studied by rapid kinetics studies, mainly by means of pulse radiolysis. ${ }^{18-21}$ A first reaction intermediate T1 would be a $\mathrm{Fe}^{3+}-\mathrm{O}-\mathrm{O}(\mathrm{H})$ species resulting from an inner-sphere reduction mechanism of $\mathrm{O}_{2}{ }^{\bullet-}$ by the ferrous iron. This is in agreement with the capability of the SOR active site to accommodate $\mathrm{Fe}^{3+}-\mathrm{O}-\mathrm{O}(\mathrm{H})$ species when reacted with $\mathrm{H}_{2} \mathrm{O}_{2},{ }^{22-25}$ 
and with a synthetic SOR model to form such species when reacted with $\mathrm{O}_{2}{ }^{\bullet-26}$ The intermediate $\mathrm{T} 1$ decays through a process ending in the formation and the release of the $\mathrm{H}_{2} \mathrm{O}_{2}$ product from the active site. Protonation processes are central in SOR catalysis since two protons, in addition to one electron, are required to form $\mathrm{H}_{2} \mathrm{O}_{2}$ from $\mathrm{O}_{2}{ }^{\bullet}$. However, rapid kinetic studies have identified only one catalytic competent protonation step, which is involved in the decay of T1. ${ }^{18-21}$ The rate constant of the decay of $\mathrm{T} 1$ in acidic medium is proportional to the concentration of protons in solution, suggesting a direct protonation of $\mathrm{T} 1$ by $\mathrm{H}_{3} \mathrm{O}^{+}$from the bulk solvent. ${ }^{18-21}$ At the end of the reaction, SOR lies in a $\mathrm{Fe}^{3+}$ hexacoordinated resting state, in which the carboxylate side chain of the E47 residue (according to the numbering of the D. baarsii enzyme) occupies the sixth coordination position. ${ }^{18-21}$

Recently, X-ray structures of iron peroxide species trapped in the active site of the SOR from $D$. baarsii have suggested a specific role for the lateral chain of the K48 residue in the control of protonation process during SOR catalysis. ${ }^{25}$ Actually, K48, a well conserved residue among SORs, is located at the surface of the protein in a conformation depending on the redox state of the active site. ${ }^{13}$ In the ferrous state, where its neighbour residue E47 is not bound to iron, $\mathrm{K} 48$ is located at about $6 \AA$ from the iron atom. ${ }^{13}$ Such close proximity of K48 was proposed to induce an electrostatic attraction of the negative charged $\mathrm{O}_{2}{ }^{\bullet-}$ to the iron site, contributing to the very fast formation of the T1 intermediate. ${ }^{18,19}$ In the ferric state, where E47 becomes a ligand of the iron, K48 moves away from the iron site, at $12 \AA$ distance. ${ }^{13}$ In the iron peroxide state, K48 can adopt different conformations around the peroxide moiety. ${ }^{25}$ In one conformation, K48, through hydrogen bond, positions a water molecule at a distance compatible with a hydrogen bond to the proximal oxygen of the hydroperoxo species. ${ }^{25}$ This suggests a mechanism involving K48 to specifically protonate the proximal oxygen of the iron-hydroperoxo intermediate to generate $\mathrm{H}_{2} \mathrm{O}_{2}$. Interestingly, in cytochrome $\mathrm{P} 450$, which also forms an iron-hydroperoxo intermediate during its catalytic cycle, a hydrogen bond network drives the protonation of the distal oxygen of the iron-hydroperoxo species. This facilitates the heterolytic cleavage of the O-O bond of the peroxide, ${ }^{15}$ which leads to the formation of a high-valent ironoxo intermediate. The iron-oxo species is responsible for the oxidation of substrates by cytochrome P450. ${ }^{15}$ In SOR, K48, by inducing the protonation of the proximal oxygen, might favour the cleavage of the $\mathrm{Fe}-\mathrm{O}$ bond of the peroxide intermediate to form $\mathrm{H}_{2} \mathrm{O}_{2}$, and thus avoiding formation of iron-oxo species in its active site. ${ }^{25}$ However, experimental evidence in support of such a function of K48 in SOR catalysis is lacking. Previous studies on K48 SOR mutants from $D$. baarsii and $D$. vulgaris Hildenborough did not reveal any significant alteration of the protonation step observable by pulse radiolysis. ${ }^{18,19}$ Nevertheless, recently, we showed that for the wild-type (wt) SOR from $D$. baarsii at $\mathrm{pH}$ 7.6, the reaction intermediate $\mathrm{T} 1$ is highly susceptible to be photodegradated by the intense light beam used in pulse radiolysis experiments below $345 \mathrm{~nm}^{21}$ This photochemical process affects the absorption spectrum of a late reaction intermediate, together with the kinetics of its evolution to the final reaction product. ${ }^{21}$ Then, the absence of effects of the K48I mutation on the reactivity of SOR with $\mathrm{O}_{2}{ }^{\bullet-}$ described in these studies is questionable and deserves more investigations. These remarks also apply for the E47A SOR mutant from $D$. baarsii, which was previously reported to have no effects on catalysis. ${ }^{19}$ The effects of this mutation also needs re-investigation in the absence of the photochemical process, in particular to allow a better analysis of the specific role of the $\mathrm{K} 48$ residue in catalysis.

Here, the reactions of the wt, E47A and K48I SORs from $D$. baarsii with $\mathrm{O}_{2}{ }^{\bullet-}$ were re-investigated by pulse radiolysis at different pHs between 5.5 and 10.2 using a $345 \mathrm{~nm}$ cut-off filter on the light beam to avoid any photochemical side reactions. ${ }^{21}$ The study reveals that the formation of the first reaction intermediate $\mathrm{T} 1$ was not affected by the K48I mutation. However, this mutation drastically impacts the reactivity of SOR towards $\mathrm{O}_{2}{ }^{\bullet-}$ through the control of a specific protonation step of the proximal oxygen of the iron hydroperoxide intermediate to produce $\mathrm{H}_{2} \mathrm{O}_{2}$. These data suggest that in the K48I SOR mutant, a high valent iron-oxo species can be formed in the active site.

\section{EXPERIMENTAL PROCEDURES}

Materials. Sodium formate and buffers were of the highest quality available (Prolabo Normatom or Merck Suprapure). Oxygen was from ALPHA GAZ. Its purity was higher than 99.99\%. Water was purified using an Elga Maxima system (resistivity $18.2 \mathrm{M} \Omega$ ). $\mathrm{K}_{2} \mathrm{IrCl}_{6}$ was from Strem Chemical Inc. Benzophenone was from Aldrich (99\%).

Protein purifications. Over-expressions and purifications of the wt, E47A and K48I SOR mutants from D. baarsii were carried out as reported previously. ${ }^{19,21}$

Pulse radiolysis. Pulse radiolysis measurements were performed as described elsewhere. ${ }^{21}$ Briefly, free radicals were generated by irradiation of $\mathrm{O}_{2}$-saturated $\left(\left[\mathrm{O}_{2}\right] \approx 1 \mathrm{mM}\right)$ aqueous protein solutions $(100 \mu \mathrm{M})$, in $2 \mathrm{mM}$ buffer, $10 \mathrm{mM}$ sodium formate with $0.2-2 \mu$ s pulses of $4.5 \mathrm{MeV}$ electrons at the linear accelerator at the Curie Institute, Orsay, France. $\mathrm{O}_{2}{ }^{\circ}$, was generated from reduction of $\mathrm{O}_{2}$ by the carboxyl radical formed during the scavenging by formate of the $\mathrm{HO}^{\circ}$ radical. $^{27}$ The doses per pulse were calibrated from the absorption of the thiocyanate radical $(\mathrm{SCN})_{2}{ }^{-}$obtained by radiolysis of $10 \mathrm{mM}$ KSCN in $\mathrm{N}_{2} \mathrm{O}$-saturated solution $\left(\mathrm{G}=0.55 \mu \mathrm{mol} . \mathrm{J}^{-1}, \varepsilon_{472}\right.$ $\left.\mathrm{nm}=7580 \mathrm{M}^{-1} \mathrm{~cm}^{-1}\right){ }^{27}$ The radiation dose varied linearly with the pulse length, for instance an $0.2 \mu$ s long pulse yielded a dose of $c a .5 \mathrm{~Gy}\left(\left[\mathrm{O}_{2}{ }^{\bullet}\right] \approx 2.8 \mu \mathrm{M}\right)$. Reactions were followed spectrophotometrically, using a $150 \mathrm{~W}$ continuous Hamamatsu SuperQuiet xenon-mercury arc $(310-750 \mathrm{~nm})$ or a tungsten lamp (450-750 nm), at $20^{\circ} \mathrm{C}$ in a $2 \mathrm{~cm}$ path length fused silica cuvette. A cut-off filter cutting all wavelengths below either $345 \mathrm{~nm}$ or below $425 \mathrm{~nm}$ was positioned between the lamp and the cuvette. ${ }^{21}$ Identical results were obtained with the 345 and the $425 \mathrm{~nm}$ filters. The kinetics of the reaction was followed spectrophotometrically between 450 and $700 \mathrm{~nm}$ on the microsecond to second time scale. The proteins were present in large excess with regard to $\mathrm{O}_{2}{ }^{\bullet-}$, providing pseudo firstorder conditions. Kinetic traces were analyzed using a Levenberg-Marquardt algorithm from the Kaleidagraph ${ }^{\circledR}$ software package (Synergy Software).

$p H$ studies. The following different buffers were used to cover the $\mathrm{pH}$ range 5.5 to $10.2 \mathrm{pH} 5.5$, acetate buffer; $\mathrm{pH}$ 5.6, 6.0, 6.5, MES buffer; $\mathrm{pH} 7.0$, bis-Tris propane or HEPES buffer; $\mathrm{pH}$ 7.6, 8.1, 8.5, 8.8, Tris-HCl buffer; $\mathrm{pH}$ 9.1, 9.5, 10.2, 10.5, glycine- $\mathrm{NaOH}$ buffer. 
Electrospray ionization mass spectroscopy. Electrospray ionization mass spectra were obtained on a Perkin-Elmer Sciex API III+ triple quadrupole mass spectrometer equipped with a nebulizer-assisted electrospray source operating at atmospheric pressure. Samples were made in $10 \mathrm{mM}$ ammonium acetate.

Hydrogen peroxide. Hydrogen peroxide was determined immediately after irradiation using the leuco crystal violet horseradish peroxidase method. ${ }^{28}$

Oxidation of 2-cyclohexen-1-ol. In a standard reaction, 0.05 to $5 \mathrm{mM}$ of $\mathrm{H}_{2} \mathrm{O}_{2}$ was mixed with $100 \mu \mathrm{M}$ of SOR, $3 \mathrm{mM} \mathrm{2-}$ cyclohexen-1-ol and $0.4 \mathrm{M}$ ethanol, in $10 \mathrm{mM}$ Tris/ $\mathrm{HCl}$ buffer $\mathrm{pH} 8.5,100 \mu \mathrm{L}$ final volume. The reaction was performed under a $100 \%$ nitrogen atmosphere (inert gloves box system Jacomex), at room temperature. After 2 to 10 min incubation, $10 \mu \mathrm{L}$ of $0.1 \mathrm{mM}$ benzophenone $99 \%$ diluted with dichloromethane was added as a reference. The reaction mixture was then extracted with dichloromethane. The organic phase was concentrated under vacuum until a volume of 5 to $10 \mu \mathrm{L}$ and injected into the gas chromatography apparatus (GC). The products were identified by comparison of their GC retention times with those of authentic synthetic compounds. For 1,2-epoxycyclohexan-3-ol (the product of 2-cyclohexen-1ol epoxidation) two peaks were detected, corresponding to the two enantiomers syn and anti. The peak of each enantiomer was identified thanks to the synthetic epoxides, which were obtained using peroxy acid, described to form the two enantiomers syn and anti in a ratio of 91:9 syn:anti. ${ }^{29}$ The gas chromatography apparatus was a PerkinElmer Autosystem (Optima-17 column, $30 \mathrm{~m}$ ), connected to a PE Nelson 1022 integrator with flame-ionization detector. The temperature program started at $100{ }^{\circ} \mathrm{C}$ for $4 \mathrm{~min}$ and then increased $25^{\circ} \mathrm{C}$ per min.

Computations. Calculations were performed using the Gaussian03 package. ${ }^{30}$ Geometries were optimized in vacuum with the B3LYP hybrid density functional ${ }^{31,32}$ and using a double- $\zeta$ quality basis set using 6-31G* for $\mathrm{C}, \mathrm{H}, \mathrm{N}, \mathrm{O}$ and $\mathrm{S}$ atoms, while a lanl2dz with $\mathrm{ECP},{ }^{33}$ augmented by an $\mathrm{f}$ polarization function of exponent 3.25 was used for iron. The model systems were taken from the crystallographic structure of the wt SOR (Protein Data Bank code: 2JI1). ${ }^{25}$ To build the systems, only the five amino-acids binding iron were considered, namely H49, H69, H75, H119 and C116. For each amino-acid, only the side chain plus $\alpha$-carbons were kept and saturated by hydrogens to replace neighbouring $\mathrm{N}$ and $\mathrm{C}$ atoms of the backbone. During the geometry optimization, $\mathrm{C} \alpha$ were kept fixed at their crystallographic positions, while hydrogens bound to them were free to move only along the $\mathrm{C} \alpha-\mathrm{N}$ or $\mathrm{C} \alpha$ $\mathrm{C}$ direction found in the crystallographic structure. By doing so, the arrangement of the active site and the local constraints imposed by the protein structure during geometry optimizations were conserved. Two systems were considered here: the pentacoordinated with iron at a formal oxidation degree of + II (no $\mathrm{O}_{2}{ }^{\bullet-}$ bound), and the hexacoordinated state, with one $\mathrm{O}_{2}{ }^{\bullet-}$ bound to the ferrous iron. UV/Visible spectra were obtained by the mean of TD-DFT methodology. ${ }^{34,35}$ Single point calculations were done on the pre-optimized structures at the B3LYP/6-311+G** level of theory, as implemented in the Gaussian package. The effects of the protein environment on the active site were accounted by the mean of the PCM implicit model of solvent ${ }^{36}$ with a dielectric constant of 4.0 and an increased probe radius of $2.7 \AA$, so as to avoid any overpolarization problems due to the presence of diffuse basis functions. For each structure, the twenty transitions of lowest energy were computed (keyword TS=NStates $=20$ ).

\section{RESULTS AND DISCUSSION}

Formation of the $T 1$ intermediate in the absence of photochemical processes

The reaction of the wt, E47A and K48I SOR mutants from $D$. baarsii with $\mathrm{O}_{2}{ }^{\circ-}$ was investigated by pulse radiolysis at different $\mathrm{pHs}$ between 5.5 and 10.2. A $345 \mathrm{~nm}$ cut-off filter was placed on the analysis light beam to prevent any photochemical reaction. ${ }^{21}$ For the three reduced proteins, the reaction conduced to the formation of a first reaction intermediate, named $\mathrm{T} 1$, with a rate constant $k_{1}$ (Scheme 1), independent of the $\mathrm{pH}$ between 5.5 to 10.2 (data not shown). These data are similar to those reported previously in the absence of the $345 \mathrm{~nm}$ filter. ${ }^{19}$ Formation of $\mathrm{T} 1$ corresponded to a bimolecular reaction of SOR with $\mathrm{O}_{2}^{\bullet-}$ with a rate constant $k_{1}$ of $(1.0 \pm 0.2) \times 10^{9} \mathrm{M}^{-1}$ $\mathrm{s}^{-1}$ for both the wt and the E47A SORs and of $(4.2 \pm 0.3) \times 10^{7}$ $\mathrm{M}^{-1} \mathrm{~s}^{-1}$ for the K48I SOR (data not shown). This latter value is 25 times lower than that reported for the wt protein, in agreement with an electrostatic guidance of $\mathrm{O}_{2}{ }^{\bullet-}$ by the positively charged K48 side chain, as previously reported. ${ }^{18,19}$

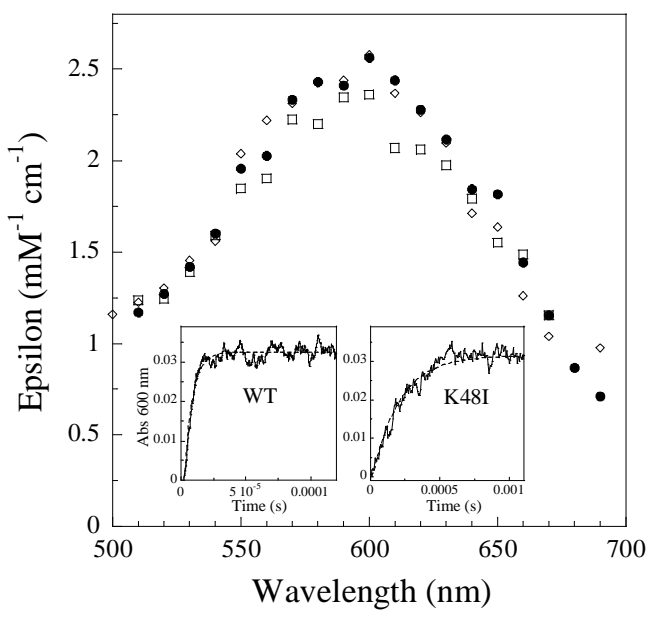

Figure 1. Transient absorption spectrum (xenon lamp with a 345 $\mathrm{nm}$ cut-off filter, $2 \mathrm{~cm}$ path-length cuvette) of the first reaction intermediate $\mathrm{T} 1$ for the wt $(\bullet)$, E47A $(\diamond)$ and K48I ( $\square$ ) SORs, formed $100 \mu \mathrm{s}$ (wt and E47A) or $1.2 \mathrm{~ms}$ (K48I) after the pulse. Proteins were $100 \mu \mathrm{M}$ in $10 \mathrm{mM}$ formate, $2 \mathrm{mM}$ Tris- $\mathrm{HCl} \mathrm{pH}$ 7.6. $\mathrm{O}_{2}{ }^{\circ-}$ concentration formed in the pulse $(11 \mathrm{~Gy})$ was $6.5 \mu \mathrm{M}$. The inset shows the time-dependent optical changes at $600 \mathrm{~nm}$ during the reaction of the wt and K48I proteins with $\mathrm{O}_{2}{ }^{\circ}$. The dashed lines were calculated for best fit to an exponential model.

The absorption spectra of $\mathrm{T} 1$ at the reaction time corresponding to its maximal formation (100 $\mu$ s for both wt and E47A SORs and $1.2 \mathrm{~ms}$ for the K48I SOR) exhibited a similar broad absorption band centred at $600 \mathrm{~nm}$, with a molar absorption coefficient value of ca. $2.5 \mathrm{mM}^{-1} \mathrm{~cm}^{-1}$ (Figure 1). In all cases, $\mathrm{T} 1$ spectrum remained unaffected by the $\mathrm{pH}$, between 5.5 and 
9.5 (data not shown), as reported previously in the absence of the 345 nm filter. ${ }^{19}$

\section{$p H$ dependence of the decay of $T 1$}

The decay of T1 (rate constant $k_{2}$, Scheme 1) was independent of the enzyme concentration (data not shown). As shown in Figure 2 , between $\mathrm{pH} 5.5$ to 8 , for the three proteins, $\log k_{2}$ exhibited a linear dependence versus $\mathrm{pH}$, with a slope of 0.50 $\pm 0.08,0.60 \pm 0.02$ and $0.70 \pm 0.05$ for the wt, E47A and K48I SORs, respectively. ${ }^{37}$ These values of slope are consistent with a rate-limiting protonation process in the decays of T1, with a proton coming from the $\mathrm{H}_{3} \mathrm{O}^{+}$bulk solvent. Above $\mathrm{pH} 8$ and up to $\mathrm{pH} 10, k_{2}$ became independent of the $\mathrm{H}^{+}$concentration for the wt SOR. Such a $\mathrm{pH}$-independent process was also reported for the enzymes from D. vulgaris and A. fulgidus and was proposed to involve a water molecule in the protonation process in more basic medium. ${ }^{18,20}$ Conversely for the E47A and K48I proteins, $k_{2}$ increased slightly with the $\mathrm{pH}$ (Figure 2). This might reflect some favourable effect of the deprotonation of surrounding residues on that step, or the involvement of $\mathrm{HO}^{-}$. Nevertheless, these data confirm that the E47A and K48I mutations do not impact the kinetics of the decay of T1, which clearly remained in acidic and neutral media associated with a rate-limiting protonation process involving $\mathrm{H}_{3} \mathrm{O}^{+}$.

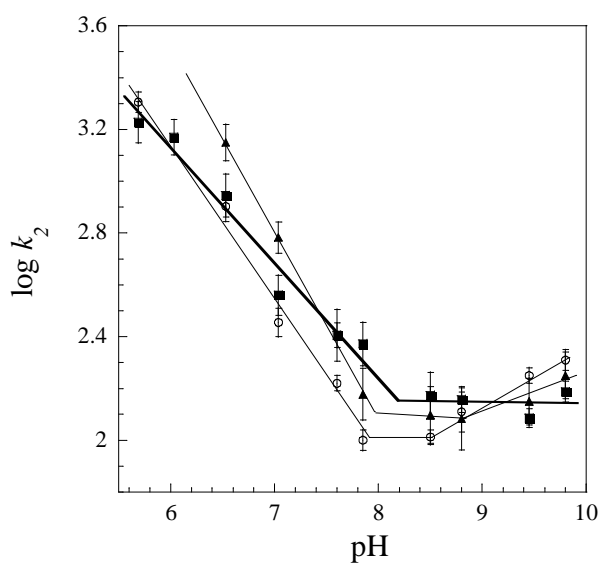

Figure 2. pH-dependence of the rate constant $k_{2}$ for the reaction of SORs from $D$. baarsii $(100 \mu \mathrm{M})$ with $\mathrm{O}_{2}{ }^{-}(3 \mu \mathrm{M})$, generated by pulse radiolysis in the presence of $10 \mathrm{mM}$ formate and $2 \mathrm{mM}$ buffer. Xenon lamp with a $345 \mathrm{~nm}$ cut-off filter. (四, bold line), wt SOR; ( $($, thin line), E47A SOR mutant; ( $\boldsymbol{\Delta}$, dashed line), K48I SOR mutant. In the range $5.5<\mathrm{pH}<8.0, \log k_{2}$ values were fitted to a linear equation, $\log k_{2}=\log k_{0}-\alpha \mathrm{pH}, \alpha=0.50 \pm 0.08$ and $k_{0}$ $=1.5 \pm 1.510^{6} \mathrm{~s}^{-1}$ (wt SOR), $\alpha=0.60 \pm 0.02$ and $k_{0}=4.7 \pm 1.0$ $10^{6} \mathrm{~s}^{-1}$ (E47A SOR mutant), $\alpha=0.70 \pm 0.05$ and $k_{0}=7.5 \pm 2.0$ $10^{7} \mathrm{~s}^{-1}$ (K48I SOR mutant). $k_{0}$ is the limit of the protonation rate constant when $\mathrm{pH}$ values approach zero.

Absorption spectra of the transient $P 1$ and the final species $P 2$ For the wt protein at $\mathrm{pH} 7.6$, the decay of T1 (rate constant $k_{2}$ ) was previously shown to result in the formation of a second transient, re-named here $\mathrm{P} 1$, which then evolved to the final SOR-Fe ${ }^{3+}$-E47 species, P2 (rate constant $k_{3}$, Scheme 1). The spectra of $\mathrm{P} 1$ and of $\mathrm{P} 2$ were determined at different $\mathrm{pHs}$ be- tween 6 and 9.5 (Figure 3). Since P1 evolved toward the formation of $\mathrm{P} 2$ before its maximal formation, the spectrum of $\mathrm{P} 1$ was calculated by an extrapolation of the kinetic traces at wavelengths between 500 and $700 \mathrm{~nm}$, using $k_{2}$ and $k_{3}$ values given in Figures 2 and 4 (see above). The spectrum of P2 was reconstructed from the absorbance value at different wavelengths at the end of the reaction.
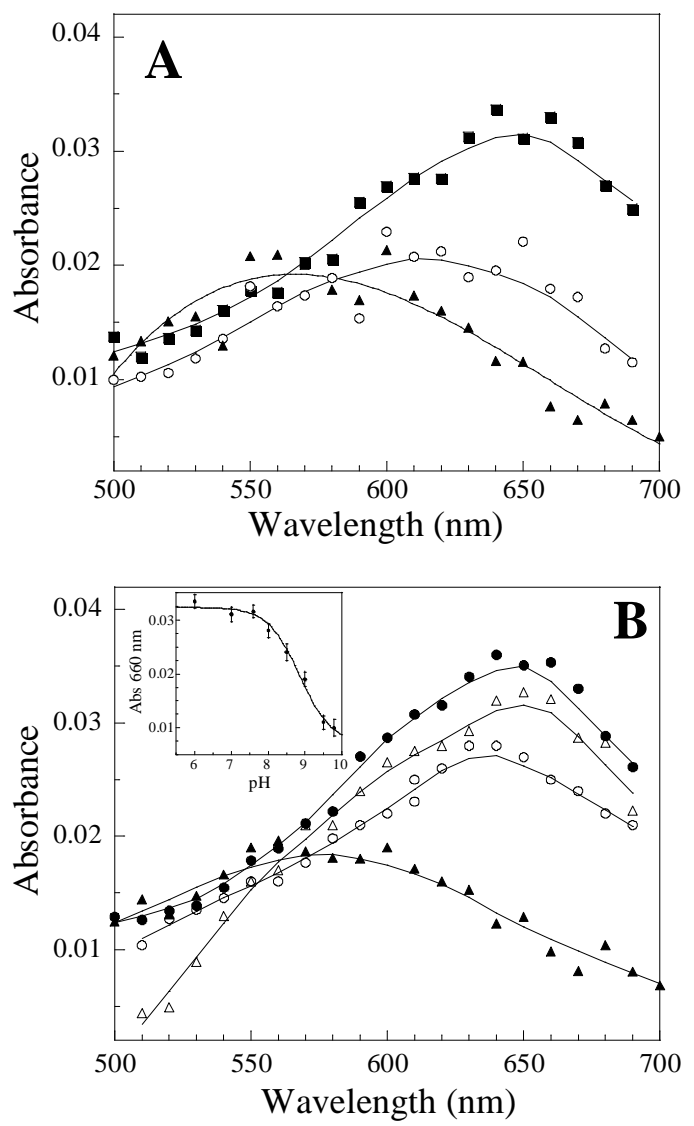

Figure 3. Absorption spectra (tungsten lamp with a $345 \mathrm{~nm}$ cutoff filter, $2 \mathrm{~cm}$ path-length cuvette) at various $\mathrm{pH}$ values of the $\mathrm{P} 1$ transient and of the final species $\mathrm{P} 2$ formed after the reaction of the SOR wt from $D$. baarsii with $\mathrm{O}_{2}{ }^{\bullet-}(8 \mu \mathrm{M})$, generated by pulse radiolysis in the presence of $10 \mathrm{mM}$ formate and $2 \mathrm{mM}$ buffer. A. Spectra of $\mathrm{P} 1$ at $\mathrm{pH} 6.0$ and $5 \mathrm{~ms}$ after the pulse (匹), $\mathrm{pH} 8.5$ and $50 \mathrm{~ms}$ after the pulse $(\circ), \mathrm{pH} 9.5$ and $60 \mathrm{~ms}$ after the pulse $(\boldsymbol{\Delta})$. The spectra were calculated from an extrapolation of the decay of T1, using the double exponential fits of the kinetic traces at different wavelengths: $\mathrm{A}=\mathrm{A}_{1} \exp \left(-k_{2} * \mathrm{t}\right)+\mathrm{A}_{2} \exp \left(-k_{3} * t\right)+\mathrm{A}_{3}$, where : $\mathrm{A}$, absorbance at time $\mathrm{t} ; \mathrm{A}_{1}$ and $\mathrm{A}_{2}$, pre-exponential terms which describe the amplitude of each phase associated with $k_{2}$ and $k_{3}$, respectively; $A_{3}$, absorbance at the end of the reaction. $A_{2}+A_{3}$ corresponds to the absorbance of $\mathrm{P} 1$ at a specific wavelength. $\mathrm{B}$. Experimental spectra of $\mathrm{P} 2$ at $\mathrm{pH} 6.0$ and $40 \mathrm{~ms}$ after the pulse $(\bullet), \mathrm{pH} 7.6$ and $70 \mathrm{~ms}$ after the pulse $(\Delta), \mathrm{pH} 8.5$ and $200 \mathrm{~ms}$ after the pulse (०), pH 9.5 and $800 \mathrm{~ms}$ after the pulse $(\boldsymbol{\Delta})$. The inset shows the $\mathrm{pH}$ dependence of the absorbance at $660 \mathrm{~nm}$. The titration curve fitted the equation expected from a single protonation process, $\mathrm{A}_{660 \mathrm{~nm}}=\left(\mathrm{A}_{660 \max }+\mathrm{A}_{660 \mathrm{~min}} \mathrm{x} 10^{(\mathrm{pH}-\mathrm{pKa})}\right) /\left(1+10^{(\mathrm{pH}-\mathrm{pKa})}\right) . A \mathrm{pK}_{\mathrm{a}}$ value of $8.9 \pm 0.2$ was determined. 
As shown in Figure 3, the absorption spectra of P1 and of P2 varied with $\mathrm{pH}$. For both species, their absorption maxima shifted from $650 \mathrm{~nm}(\mathrm{pH}<8.5)$ to $560 \mathrm{~nm}(\mathrm{pH} \mathrm{9.5)} \mathrm{and} \mathrm{were}$ superimposable to those reported for the alkaline transition of the SOR ferric active site. ${ }^{19}$ The alkaline transition is associated with an acid-base equilibrium between the $\mathrm{Fe}^{3+}-\mathrm{E} 47$ (wt SOR) or the $\mathrm{Fe}^{3+}-\mathrm{OH}_{2}$ (E47A mutant) species present in acidic medium (band at $650 \mathrm{~nm}$ ) and the $\mathrm{Fe}^{3+}-\mathrm{OH}$ species present in more basic medium (band at $560 \mathrm{~nm}$ ). ${ }^{19,38}$ For P1, taking into account the uncertainty associated with the calculation of its spectrum, in particular at neutral $\mathrm{pH}$ (in this $\mathrm{pH}$ domain, $k_{2}$ and $k_{3}$ values were close to each other), a $\mathrm{pK}_{\mathrm{a}}$ value for the 650-560 nm transition could not be determined accurately. For $\mathrm{P} 2$, the $650-560 \mathrm{~nm}$ transition appeared to occur with a $\mathrm{pK}_{\mathrm{a}}$ value of $8.9 \pm 0.2$ (Inset Figure 3B), similar to that reported for the SOR ferric active site. ${ }^{19}$ These data are fully consistent with the formation of the $\mathrm{Fe}^{3+}-\mathrm{E} 47 / \mathrm{Fe}^{3+}-\mathrm{OH}$ species at the end of the reaction. Comparison of the spectra of $\mathrm{P} 1$ and of the $\mathrm{Fe}^{3+}-\mathrm{E} 47 / \mathrm{Fe}^{3+}-\mathrm{OH}$ final species at different $\mathrm{pHs}$ (Figures $3 \mathrm{~A}$ and $3 \mathrm{~B}$ ) suggests however that the $\mathrm{pK}_{\mathrm{a}}$ of the $\mathrm{P} 1$ transition is lower than that of $\mathrm{P} 2$.

The decay of P1 into P2 (rate constant $k_{3}$, Scheme 1) was found to be independent of the enzyme concentration (data not shown). As shown in Figure 4, the rate constant $k_{3}$ varied with $\mathrm{pH}$, with a pKa value of $7.2 \pm 0.1$.

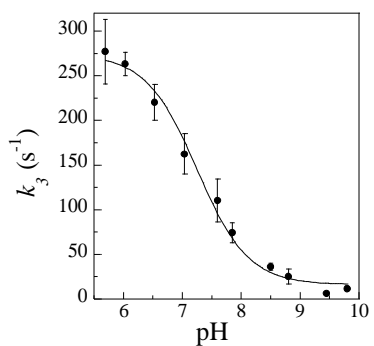

Figure 4. $\mathrm{pH}$-dependence of the rate constant $k_{3}$ for the reaction of the wt SOR from $D$. baarsii $(100 \mu \mathrm{M})$ with $\mathrm{O}_{2}{ }^{\bullet-}(8-12 \mu \mathrm{M})$, generated by pulse radiolysis in the presence of $10 \mathrm{mM}$ formate and 2 $\mathrm{mM}$ buffer. Tungsten lamp with a $345 \mathrm{~nm}$ cut-off filter. The titration curve fitted the equation expected from a single protonation process, $k_{3}=\left(k_{3 \max }+k_{3 \min } \times 10^{(\mathrm{pH}-\mathrm{pKa})}\right) /\left(1+10^{(\mathrm{pH}-\mathrm{pKa})}\right) . \mathrm{A} \mathrm{pK}_{\mathrm{a}}$ value of $7.2 \pm 0.1$ was determined.

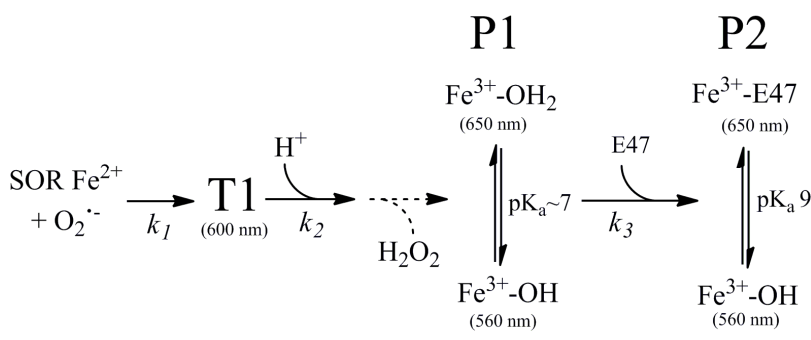

Scheme 1. Reaction mechanism of the SOR from $D$. baarsii with $\mathrm{O}_{2}{ }^{\bullet-}$ deduced from pulse radiolysis studies. T1 is the only competent reaction intermediate observed by pulse radiolysis. $\mathrm{P} 1$ and $\mathrm{P} 2$ are reaction products formed after the release of $\mathrm{H}_{2} \mathrm{O}_{2}$ from the active site.

\section{Pl as the final species for the E47A SOR mutant}

For the E47A mutant, at all the $\mathrm{pH}$ investigated between 5.5 and 10.2 , the decay of T1 $\left(k_{2}\right)$ led directly to the formation of a final species, without evidence of a third reaction step (no $k_{3}$ observed). The absorption spectrum of the final species was reconstructed at $\mathrm{pH} 5.5$ and 8.5 and was found to be superimposable to that of the final oxidized E47A mutant at the same $\mathrm{pH}$, with a maximum of absorption shifted from $650 \mathrm{~nm}$ at $\mathrm{pH}$ 5.5 to $560 \mathrm{~nm}$ at $\mathrm{pH} 8.5$ (Figure 5A). These spectra appeared similar to those of $\mathrm{P} 1$ in the wt protein, taking into account the uncertainty associated with the calculation the spectra of P1 (Figure 3A). As shown in Figure 5B, the dependence of the final absorbance at $640 \mathrm{~nm}$ on the $\mathrm{pH}$ allowed calculating a $\mathrm{pK}_{\mathrm{a}}$ value of $6.7 \pm 0.2$ for the transition between the 650 and $560 \mathrm{~nm}$ absorbing species. This value is identical to the $\mathrm{pK}_{\mathrm{a}}$ reported for the similar spectral transition of the E47A SOR ferric site, corresponding to a $\mathrm{Fe}^{3+}-\mathrm{OH}_{2} / \mathrm{Fe}^{3+}-\mathrm{OH}$ acid-base equilibrium. ${ }^{19,38}$
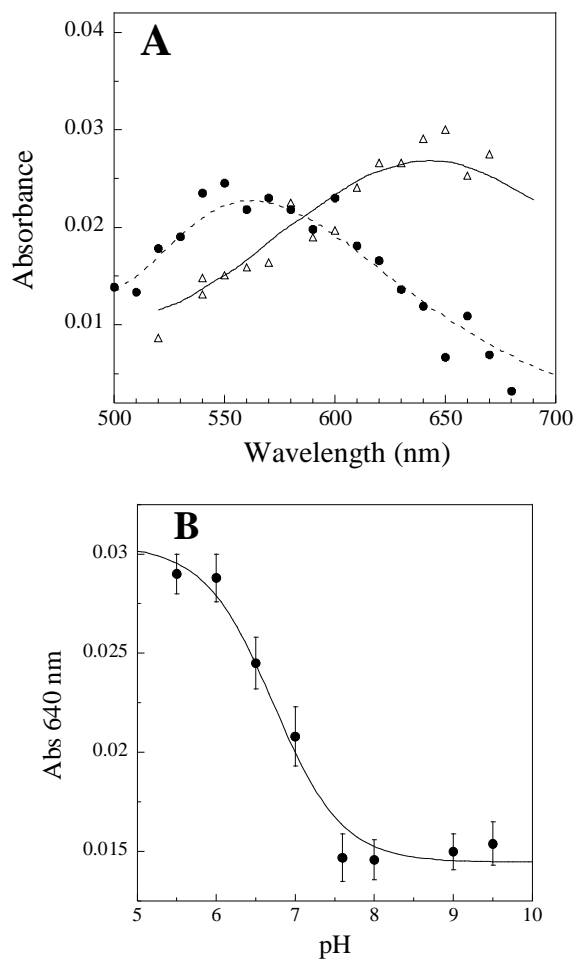

Figure 5. A. Absorption spectra of the final species formed at different $\mathrm{pHs}$ after the reaction of the E47A SOR mutant with $\mathrm{O}_{2}{ }^{\bullet-}(8 \mu \mathrm{M})$, generated by pulse radiolysis in the presence of 10 $\mathrm{mM}$ formate and $2 \mathrm{mM}$ buffer. $(\Delta) \mathrm{pH} 5.5,4 \mathrm{~ms}$ after the pulse. $(\bullet) \mathrm{pH} 8.5,80 \mathrm{~ms}$ after the pulse. Tungsten lamp with a $345 \mathrm{~nm}$ cut-off filter, $2 \mathrm{~cm}$ path-length cuvette. The absorption spectrum in $2 \mathrm{~cm}$ path-length cuvette of the iridium chloride oxidized E47A SOR mutant $(8 \mu \mathrm{M})$ is shown at $\mathrm{pH} 5.5$ (solid line) and at $\mathrm{pH} 8.5$ (dotted line). B. pH-dependence of the final absorbance at $640 \mathrm{~nm}$ measured after the reaction of the E47A SOR mutant from $D$. baarsii $(100 \mu \mathrm{M})$ with $\mathrm{O}_{2}{ }^{-}(8 \mu \mathrm{M})$, under the same conditions. The titration curve fits the equation expected from a single protonation process, $\mathrm{A}_{640 \mathrm{~nm}}=\left(\mathrm{A}_{640 \max }+\mathrm{A}_{640 \min } \times 10^{(\mathrm{pH}-\mathrm{pKa})}\right) /\left(1+10^{(\mathrm{pH}-}\right.$ $\left.{ }_{\mathrm{pKa})}\right)$. $\mathrm{A} \mathrm{pK}_{\mathrm{a}}$ value of $6.7 \pm 0.2$ was determined. 
Thus, for this mutant, $\mathrm{P} 1$ is identified to the couple $\mathrm{Fe}^{3+}-\mathrm{OH}_{2} /$ $\mathrm{Fe}^{3+}-\mathrm{OH}$ (Scheme 1). Since the third reaction (rate constant $k_{3}$ ) was specifically abolished by the E47A mutation, the formation of $\mathrm{P} 2$ can be associated to the binding of the E47 carboxylate group on $\mathrm{P} 1$, displacing the $\mathrm{OH} / \mathrm{OH}_{2}$ ferric iron ligand. The dependence of the rate constant $k_{3}$ on the $\mathrm{pH}$ (Figure 4) most likely reflects a more favourable ligand exchange of the E47 with the $-\mathrm{OH}_{2}$ species than with the $-\mathrm{OH}$ species. Thus, the $\mathrm{pK}_{\mathrm{a}}$ associated with the rate constant $k_{3}(\mathrm{P} 1 \rightarrow \mathrm{P} 2)$ can be associated with the $\mathrm{Fe}^{3+}-\mathrm{OH}_{2} / \mathrm{Fe}^{3+}-\mathrm{OH}$ acid-base equilibrium on P1 (Scheme 1). Accordingly, its value (7.2 \pm 0.1 , Figure 4) is close to the $\mathrm{pK}_{\mathrm{a}}$ value determined for the alkaline transition of the ferric E47A SOR mutant $(6.7 \pm 0.2) .{ }^{19}$ It should be noted that since $k_{3}$ was still observed at $\mathrm{pH}>9.5$ (Figure 4), $\mathrm{P} 1$ and $\mathrm{P} 2$ species could not be in equilibrium with a same $\mathrm{Fe}^{3+}-\mathrm{OH}$ species (Scheme 1). Thus, although the $\mathrm{Fe}^{3+}-\mathrm{OH}$ species in $\mathrm{P} 1$ and P2 exhibit similar absorption spectra, they may not be equivalent, with a slightly different protein environment.

Scheme 1 summarizes the reaction mechanism of SOR from D. baarsii, as deduced from pulse radiolysis studies on the wt and E47A proteins in the absence of photochemical process. This reaction scheme appears very similar to that reported for the SORs from A. fulgidus, ${ }^{20}$ suggesting, as discussed in previous work, ${ }^{21}$ an overall common reaction mechanisms for the different SORs studied so far. It is important to underline that according to Scheme 1, T1 appeared as the only competent reaction intermediate observed by pulse radiolysis. In fact $\mathrm{P} 1$, associated with a $\mathrm{Fe}^{3+}-\mathrm{OH}_{2}$ or $\mathrm{Fe}^{3+}-\mathrm{OH}$ species, is a reaction product, resulting from the release of $\mathrm{H}_{2} \mathrm{O}_{2}$ from the active site. Actually, only one catalytic protonation step (rate constant $k_{2}$ ) was observed by pulse radiolysis. Thus, the other protonation process required to generate $\mathrm{H}_{2} \mathrm{O}_{2}$ from $\mathrm{O}_{2}{ }^{\bullet-}$ was not observed, and should correspond to a non-rate limiting step. That $\mathrm{T} 1$ could be already a protonated species, such as an iron hydroperoxo species and that $\mathrm{H}_{2} \mathrm{O}_{2}$ formation might directly result from the protonation of $\mathrm{T} 1$ was previously proposed. $^{20,39}$ However, formation of $\mathrm{T} 1$, which occurred at a nearly diffusion-controlled rate $\left(\approx 10^{9} \mathrm{M}^{-1} \mathrm{~s}^{-1}\right)$, was found to be totally independent on $\mathrm{pH}$ from $\mathrm{pH} 5$ to $\mathrm{pH} 10$, thus over a variation of 100,000 fold in the concentration of $\mathrm{H}^{+}$in the solution. ${ }^{18-21}$ Consequently, formulation of $\mathrm{T} 1$ as a protonated species is questionable.

\section{Formation of the final species for the K48I SOR mutant}

The spectrum resulting from the decay of T1 in the K48I mutant was reconstructed at different $\mathrm{pHs}$ (Figure 6). At $\mathrm{pH} 5.6$, a spectrum similar to that of P1 was observed, with however only $40 \%$ of the intensity of that of the wt at the same $\mathrm{pH}$. This species in the K48I SOR mutant evolved to an end product, which had similar spectral features than P2, with an intensity about $40 \%$ less than that of the wt at the same $\mathrm{pH}$ (data not shown). Surprisingly, when increasing the $\mathrm{pH}$, in the K48I SOR mutant, the intensity of the absorbances of P1 and P2 became smaller and smaller and were almost annihilated at $\mathrm{pH}$ 8.5 and above (Figure 6).

Pulse radiolysis experiments were then carried out at $\mathrm{pH} 8.5$, where the $\mathrm{K} 48 \mathrm{I}$ mutant $(8 \mu \mathrm{M})$ was reacted with a stoichiometric amount of $\mathrm{O}_{2}^{\bullet-}(8 \mu \mathrm{M}, 12.5 \mathrm{~Gy})$. These conditions allowed recording directly the absorption spectrum of the solution $c a$. $1 \mathrm{~min}$ after the pulse with a classical spectrophotometer. The presence or absence of a catalytic amount of catalase added to the solution before the pulse had no effect on the final absorption spectrum (data not shown).

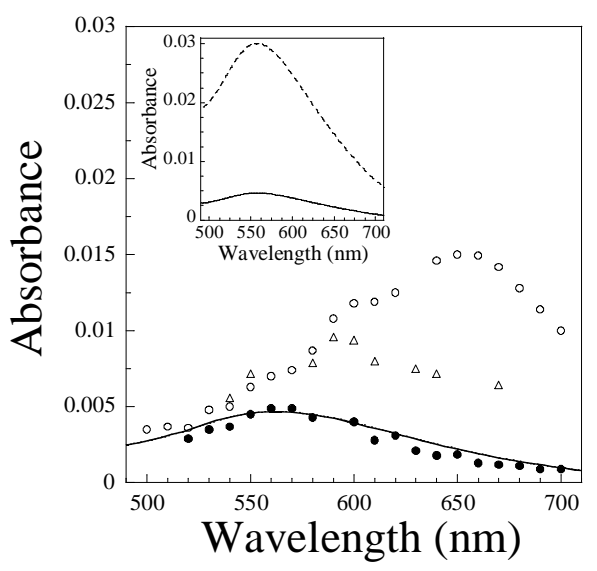

Figure 6. Absorption spectra at different $\mathrm{pHs}$ of the final species for the reaction of the K48I SOR mutant from $D$. baarsii $(100$ $\mu \mathrm{M})$ with $\mathrm{O}_{2}{ }^{\bullet-}(8 \mu \mathrm{M})$, generated by pulse radiolysis in the presence of $10 \mathrm{mM}$ formate and $2 \mathrm{mM}$ buffer. Tungsten lamp with a $345 \mathrm{~nm}$ cut-off filter, $2 \mathrm{~cm}$ path-length cuvette. The spectra were reconstructed at the following $\mathrm{pHs}$ and times after the pulse: $\mathrm{pH}$ 5.6 and $20 \mathrm{~ms}(\circ), \mathrm{pH} 7.6$ and $500 \mathrm{~ms}(\Delta), \mathrm{pH} 8.5$ and $500 \mathrm{~ms}$ $(\bullet)$. The solid line shows the spectrum of the solution at $\mathrm{pH} 8.5$ recorded on a UV-visible spectrophotometer $1 \mathrm{~min}$ after the pulse. The inset shows the same spectrum of the solution at $\mathrm{pH} 8.5$ recorded on a UV-visible spectrophotometer $1 \mathrm{~min}$ after the pulse, without (solid line) and with treatment with a slight molar excess of $\mathrm{K}_{2} \mathrm{IrCl}_{6}$ (dotted line).

The solution thus obtained showed a spectrum identical to that reported in Figure 6 for the species formed at $\mathrm{pH} 8.5$ and at $500 \mathrm{~ms}$ reaction time $((\bullet)$, Figure 6$)$. This showed that this spectrum corresponds to that of a stable final species. When the pulsed K48I SOR mutant solution at $\mathrm{pH} 8.5$ was reoxidized $c a .1 \mathrm{~min}$ after the pulse with a slight stoichiometric excess of $\mathrm{K}_{2} \mathrm{IrCl}_{6}$, the spectrum showed a strong increase of the band in the $560 \mathrm{~nm}$ region. This band was superimposable to that of a solution of K48I mutant active site $(8 \mu \mathrm{M})$ oxidized by $\mathrm{K}_{2} \mathrm{IrCl}_{6}$ at the corresponding $\mathrm{pH}$ (Inset of Figure 6). Electrospray mass spectra analysis of the K48I SOR mutant after the pulse radiolysis experiment gave a value of 14,010 \pm $1 \mathrm{Da}$ for the mass of its polypeptide chain. This value is expected for the K48I SOR mutant, showing that its polypeptide chain was no altered at the end of the reaction.

Altogether, these data indicate that the weak or almost absence of the absorbance band at the end of the reaction of the K48I SOR mutant with $\mathrm{O}_{2}{ }^{\bullet-}$ in basic medium did not reflect a degradation of SOR, but the formation of a ferrous iron active site species. In fact, the ferrous iron site has no absorption band in the visible region. ${ }^{5}$ Consequently, from the spectra of Figure 6 at $\mathrm{pH} 5.6$, one can calculate that at the end of the reaction of the K48I mutant with $\mathrm{O}_{2}{ }^{\circ-}, 40 \%$ of the enzyme was oxidized $(3.2 \mu \mathrm{M})$ and $60 \%$ reduced $(4.8 \mu \mathrm{M})$. At $\mathrm{pH} 8.5$, at the end of the reaction, $85 \%$ of the mutant was reduced $(6.8 \mu \mathrm{M})$ and $15 \%$ oxidized $(1.2 \mu \mathrm{M})$. Then, the higher the $\mathrm{pH}$ at which the 
reaction of the K48I SOR mutant with $\mathrm{O}_{2}{ }^{--}$was carried out, the more the SOR iron site ended up on a reduced state, $\mathrm{Fe}^{2+}$.

Quantification of $\mathrm{H}_{2} \mathrm{O}_{2}$ production immediately after the pulse was carried out at $\mathrm{pH} 8.5$ using the leuco crystal violethorseradish peroxidase method. ${ }^{28}$ As shown in Table 1, at $\mathrm{pH}$ 8.5, the formation of $\mathrm{H}_{2} \mathrm{O}_{2}$ resulting from the reaction of $\mathrm{O}_{2}{ }^{\bullet-}$ with the K48I SOR mutant represented only about $15 \%$ of the expected value for a stoichiometric reaction of SOR with $\mathrm{O}_{2}{ }^{\bullet-}$.

It should be noted that $\mathrm{T} 1$ was formed in the same amount in the K48I SOR mutant compared to the wt (Figure 1). Consequently, the near-absence of the formation of $\mathrm{H}_{2} \mathrm{O}_{2}$ at basic pHs cannot be associated with the decrease of the rate constant of the reaction of the mutant with $\mathrm{O}_{2}{ }^{\bullet-}$.

Altogether, these data show that the K48I mutation has a profound effect on the reaction of SOR with $\mathrm{O}_{2}{ }^{\bullet-}$. Although the K48I mutant does not modify the spectrum of the T1 intermediate and its $\mathrm{pH}$ dependent decay (Figures 1 and 2), in basic medium it does not lead to the formation of the ferric species. Instead, it leads to the formation of a ferrous SOR species, without production of $\mathrm{H}_{2} \mathrm{O}_{2}$.

Table 1. Amount of $\mathrm{H}_{2} \mathrm{O}_{2}$ produced immediately after the reaction of the K48I SOR mutant $(20 \mu \mathrm{M})$ with various concentration of $\mathrm{O}_{2}{ }^{\bullet-}$, at $\mathrm{pH} 8.5$.

\begin{tabular}{|c|c|c|}
\hline $\begin{array}{c}{\left[\mathrm{O}_{2}{ }^{\circ-}\right]} \\
\text { reacted } \\
\text { with SOR } \\
(\mu \mathrm{M})\end{array}$ & $\begin{array}{c}{\left[\mathrm{H}_{2} \mathrm{O}_{2}\right] \text { pro- }} \\
\text { duced } \\
(\mu \mathrm{M})\end{array}$ & $\begin{array}{c}{\left[\mathrm{H}_{2} \mathrm{O}_{2}\right] \text { produced } /\left[\mathrm{O}_{2}{ }^{\circ}\right]} \\
\text { reacted with SOR } \\
(\%)\end{array}$ \\
\hline 3.4 & 0.5 & 15 \\
\hline 4.4 & 0.4 & 9 \\
\hline 6.3 & 1.2 & 19 \\
\hline 6.8 & 1.2 & 17 \\
\hline \multicolumn{2}{|c|}{} \\
\hline $\mathrm{O}_{2}{ }^{\circ-}$ was generated by pulse radiolysis $(10 \mathrm{mM}$ formate, $2 \mathrm{mM}$
\end{tabular}
Glycine $\mathrm{NaOH}$ buffer $\mathrm{pH} 8.5,1 \mathrm{mM} \mathrm{O} \mathrm{O}_{2}$. $\mathrm{H}_{2} \mathrm{O}_{2}$ was determined from the oxidation of LCV in the presence of horse radish peroxidise. ${ }^{28}$ b Values were corrected from the production of $\mathrm{H}_{2} \mathrm{O}_{2}$ formed from the onset of water radiolysis $\left(\mathrm{G} \approx 0.07 \mu \mathrm{mol} \mathrm{J}^{-1}\right)$.

Epoxidation of 2-cyclohexen-1-ol catalyzed by SOR. Evidence for the formation of iron-oxo species in SOR

For the K48I SOR mutant, the formation of a final $\mathrm{Fe}^{2+}$ species without production of $\mathrm{H}_{2} \mathrm{O}_{2}$, as observed at $\mathrm{pH} 8.5$ (Figure 6 and Table 1), might be the consequence of oxidation of organic solutes present in the solution, formate or buffer, carried out by a transient species formed at its active site. In order to investigate if the K48I SOR mutant could perform such oxidation reactions, we tested its ability to oxidize olefin, 2cyclohexen-1-ol as a test substrate, in the presence of $\mathrm{H}_{2} \mathrm{O}_{2}$ at $\mathrm{pH}$ 8.5. Oxidation of olefins has been well described to characterize reactions catalyzed by iron complexes, in particular for those forming iron-oxo intermediates. ${ }^{40-42}$ The reaction was conducted at room temperature under anaerobic conditions, in the presence of 5 to 50 molar equivalent of $\mathrm{H}_{2} \mathrm{O}_{2}$ and 30 molar equivalent of racemic 2-cyclohexen-1-ol, with respect to SOR (Table 2). In the absence of SOR or in the presence of the wt protein or the E47A SOR mutant, no oxidation products of 2cyclohexen-1-ol were detected (Table 2). On the other hand, in the presence of the K48I SOR mutant and 10 to 50 molar equivalent of $\mathrm{H}_{2} \mathrm{O}_{2}$, 2-cyclohexen-1-ol was oxidized into epoxide, in a $25-30 \%$ yield, assuming a stoichiometric reaction of SOR with the olefin (Table 2). No other oxidation product, e.g. the ketone 2-cyclohexen-1-one, was detected. The epoxide formed in the presence of the K48I SOR mutant contained a slight diastereoisomer excess of $20 \%$ for the anti isomers, corresponding to the enantiomers $(1 \mathrm{~S}, 2 \mathrm{R}, 6 \mathrm{R})$ and $(1 \mathrm{R}, 2 \mathrm{~S}$, 6S) 7-oxabicyclo[4-1-0] heptan 2-ol. When the reaction time was lengthened to $10 \mathrm{~min}$, no variation in the amount of epoxide formed was observed (data not shown), showing that the oxidation reaction was over within 2 min.

UV-visible spectral analysis of the solution at 2 min reaction time revealed that the SOR active site got mostly destroyed, whether the olefin was present or not (wt and K48I SOR mutant proteins, Table 2). It should be noted that such denaturation processes precluded any possible turn-over reactions in the oxidation of olefin.

These data demonstrate that the mutation of lysine 48 into isoleucine leads to new properties of SOR, allowing it to carry out $2 \mathrm{e}^{-}$oxidation of organic substrates in the presence of $\mathrm{H}_{2} \mathrm{O}_{2}$. As mentioned previously, the SOR active site is able to form iron peroxide species when treated with an excess of $\mathrm{H}_{2} \mathrm{O}_{2}{ }^{22-25}$ However, that an iron peroxide species in the K48I SOR mutant could be directly involved in the oxidation reaction is unlikely. In fact, such iron peroxide species were shown to be poor oxidant, not prone to carry out oxidation reaction of sulfide and olefin. ${ }^{40,41,43}$ On the other hand, high-valent iron-oxo species, generated via $\mathrm{O}-\mathrm{O}$ bond cleavage of the iron-peroxide species in iron complexes, are known to be the active species in the oxidation of organic substrates. ${ }^{40-43}$ These data suggested that in the K48I SOR mutant, the $\mathrm{Fe}^{3+}-\mathrm{O}-\mathrm{OH}$ species formed upon reaction with $\mathrm{H}_{2} \mathrm{O}_{2}$ undergoes a cleavage of its $\mathrm{O}-\mathrm{O}$ bond to generate an iron-oxo species. Whether this cleavage could be homolytic or heterolytic to generate $\mathrm{Fe}(\mathrm{IV})=\mathrm{O}+$ $\mathrm{HO}^{\bullet}$ or $\mathrm{Fe}(\mathrm{V})=\mathrm{O}+\mathrm{HO}^{-}$species respectively, is still unknown. Nevertheless, our data showed no evidence for the involvement of $\mathrm{HO}^{\bullet}$ in the oxidation reaction. As a matter of fact, epoxidation reaction involves an oxygen transfer to a C-C double bond, corresponding to a $2 \mathrm{e}^{-}$oxidation. One electron oxidant species such as $\mathrm{HO}^{\bullet}$ are not prone to carry out such reaction. In addition, the high chemoselectivity toward epoxidation and the presence of diastereoisomeric excess of the anti isomers are not in favour of a free radical chemistry. Thus, these data indicated for the K48I SOR mutant a metal-based mechanism, possibly an iron-oxo species directly involved in the $2 \mathrm{e}^{-}$oxidation of 2-cyclohexen-1-ol. Hence, in the SOR from $D$. baarsii, the K48I mutation would favour formation of a highly oxidant iron-oxo species in its active site.

The demonstration that the K48I SOR mutant can perform oxidation reaction provides an explanation for the formation of a $\mathrm{Fe}^{2+}$ species without production of $\mathrm{H}_{2} \mathrm{O}_{2}$ at the end of the reaction of the mutant with $\mathrm{O}_{2}^{\circ-}$ (Figure 6 and Table 1). This $\mathrm{Fe}^{2+}$ species could result from a $2 \mathrm{e}^{-}$oxidation reaction of organic solutes present in the solution used in pulse radiolysis, namely formate, tris-hydroxymethyl aminomethane or glycine, carried out by a $\mathrm{Fe}(\mathrm{IV})=\mathrm{O}$ species formed through homolytic cleavage of an iron peroxide intermediate (Scheme 2). 
Table 2. Yields (\%/SOR) of epoxide formation from the oxidation of 2-cyclohexen-1-ol by $\mathrm{H}_{2} \mathrm{O}_{2}$, in the presence of wt or K48I SOR mutant proteins from $D$. baarsii

\begin{tabular}{|c|c|c|c|}
\hline SOR & $\begin{array}{c}\mathrm{H}_{2} \mathrm{O}_{2} \\
\text { (equiv./SOR) }\end{array}$ & $\begin{array}{c}\text { epoxide } \\
\text { (yield/SOR) }\end{array}$ & $\begin{array}{c}\text { \% of de- } \\
\text { struction of } \\
\text { SOR active } \\
\text { site }^{1}\end{array}$ \\
\hline no SOR & 50 & 0 & nd \\
\hline \multirow{2}{*}{ wt } & 5 & 0 & nd \\
\cline { 2 - 4 } & 10 & 0 & $\sim 60$ \\
\cline { 2 - 4 } & 30 & 0 & 100 \\
\cline { 2 - 4 } & 50 & 0 & 100 \\
\hline \multirow{2}{*}{$\begin{array}{c}\text { E47A } \\
\text { mutant }\end{array}$} & 10 & 0 & nd \\
\cline { 2 - 4 } K48I \\
mutant
\end{tabular}

Conditions: $100 \mu \mathrm{M}$ SOR, $3 \mathrm{mM}$ 2-cyclohexen-1-ol, $0.4 \mathrm{M} \mathrm{EtOH}$, $10 \mathrm{mM}$ Tris $/ \mathrm{HCl}, \mathrm{pH}$ 8.5. Epoxide was detected by gas chromatography 2 minutes after the addition of $\mathrm{H}_{2} \mathrm{O}_{2}$. The reaction with $\mathrm{H}_{2} \mathrm{O}_{2}$ was carried out at room temperature and under anaerobic conditions (100\% $\mathrm{N}_{2}$ atmosphere). Nd: not determined. ${ }^{1}$ From UV-visible spectra analysis of the solution at 2 min reaction time. The spectra of the solution were recorded before and after $\mathrm{K}_{2} \mathrm{IrCl}_{6}$ treatments, in order to discriminate between reduced SOR, which exhibits an absorbance band in the 560-650 nm regions after oxidation with $\mathrm{K}_{2} \mathrm{IrCl}_{6}$, and degraded SOR, which does not show any increase of absorbance in the 560-650 nm regions after oxidation with $\mathrm{K}_{2} \mathrm{IrCl}_{6}$. Identical results were obtained in the presence or in the absence of 2-cyclohexen-1-ol. ${ }^{2}$ Low amounts of epoxide were detected, that could not be accurately quantified. ${ }^{3}$ Epoxide formed with a diastereoisomer excess of $20 \%$ for the anti isomers, corresponding to the enantiomers $(1 \mathrm{~S}, 2 \mathrm{R}, 6 \mathrm{R})$ and $(1 \mathrm{R}, 2 \mathrm{~S}$, 6S) 7-oxabicyclo[4-1-0] heptan 2-ol.

These data highlight a pivotal role for K48 in the control of the evolution of the reaction intermediate during the reaction of SOR with $\mathrm{O}_{2}{ }^{\bullet-}$. This role is in full agreement with the X-ray structures of the iron peroxide species in SOR, which suggests the involvement of K48 in a specific protonation of the proximal oxygen of the iron hydroperoxide intermediate, to generate the reaction product $\mathrm{H}_{2} \mathrm{O}_{2}$. ${ }^{25}$ Our data suggest that in the absence of $\mathrm{K} 48$, the protonation of the proximal oxygen of the peroxide intermediate does not occur, thus favouring a cleavage of the $\mathrm{O}-\mathrm{O}$ bond of the iron peroxide intermediate to generate an iron-oxo species. In cytochrome P450, it has been shown that a hydrogen bond network induced a double protonation of the distal oxygen of the iron peroxide intermediate, favouring the cleavage of the $\mathrm{O}-\mathrm{O}$ bound of the peroxide moiety and formation of the high-valent iron-oxo species (compound 1). ${ }^{15}$ That such a double protonation of the distal oxygen of the peroxide might occur in the K48I SOR mutant is not known, but might be considered taking into account the solvent exposed active site of SOR and the presence of water molecule in the X-ray structure of SOR with the peroxide adduct hydrogen bonded to its distal oxygen atom. ${ }^{25}$ Other factors, such as the spin state of the iron peroxide species, high spin for SOR ${ }^{44,45}$ or low spin for cytochrome P450, ${ }^{15}$ were also proposed to be important to control the evolution of the iron-peroxide intermediate. However, our results provide evidence for the ability to the SOR active site to form iron-oxo species and that the tight control of the protonation of the peroxide intermediate might be the determining factor to avoid formation of such highly oxidizing species.

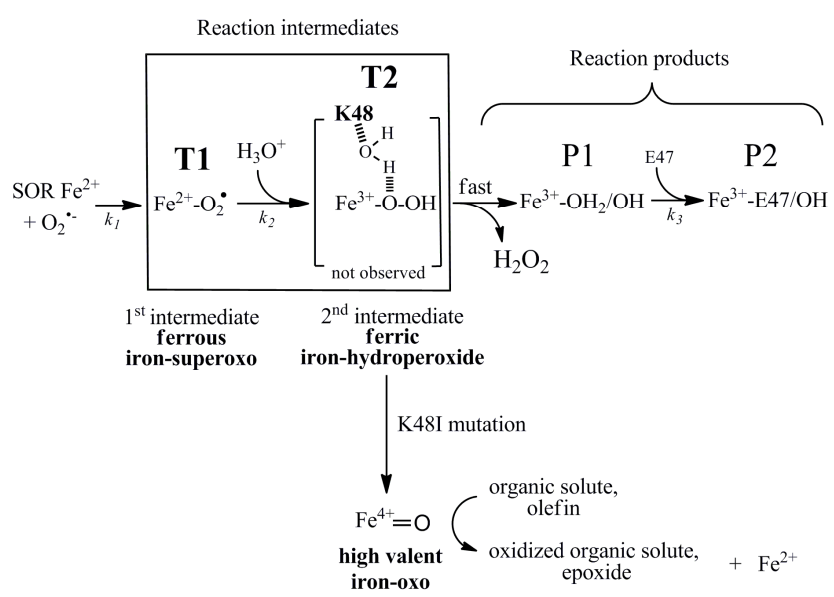

Scheme 2. Proposed mechanism for the reaction of SOR with $\mathrm{O}_{2}{ }^{\bullet-}$, involving $\mathrm{K} 48$ in the second protonation process. T1 and $\mathrm{T} 2$, formulated as ferrous iron-superoxo and ferric iron hydroperoxide species, respectively, are the two reaction intermediates which lead to the formation of $\mathrm{H}_{2} \mathrm{O}_{2}$. T2 decays in a non-rate limiting step involving $\mathrm{K} 48$, and it is not observed by rapid kinetic studies.

The first reaction intermediate $T 1$ is a ferrous iron-superoxo species. TD-DFT calculation on its absorption spectrum

Our present data showed that K48 is not involved in the unique protonation step observed by pulse radiolysis (Figure 2). These data suggest that K48 is involved in the second protonation step not observed in rapid kinetics. This step would be a fast, non-rate limiting process, leading to the formation of a ferric iron hydroperoxide species, denoted T2 in Scheme 2. The structure of T2 could correspond to the X-ray structure of the iron peroxide intermediate trapped in monomer D in the crystal of SOR from $D$. baarsii, where a water molecule hydrogen bonded to $\mathrm{K} 48$ was closely positioned to the proximal oxygen of the hydroperoxide intermediate. ${ }^{25}$ Such conformation could be in agreement with a fast, non-rate limiting protonation process by this water molecule of the hydroperoxide moiety to form $\mathrm{H}_{2} \mathrm{O}_{2}$. That such an instable species was trapped in the crystal could be associated with its stabilisation by the local packing forces. ${ }^{25}$

The proposition of two protonation steps following the formation of T1 has also important consequences concerning the chemical structure of T1 (Scheme 2). T1, which resulted from the binding of $\mathrm{O}_{2}^{-\bullet}$ to the sixth free coordination position of the ferrous iron center, has to be now formulated as a nonprotonated species. Consequently, $\mathrm{T} 1$ could be either a $\mathrm{Fe}^{3+}-\mathrm{O}-$ $\mathrm{O}^{-}$or a $\mathrm{Fe}^{2+}-\mathrm{O}_{2}{ }^{\bullet}$ species, depending on the fact that the electron transfer from the ferrous iron to the $\mathrm{O}_{2}{ }^{\bullet-}$ adduct occurred 
or not in this non-protonated species. Interestingly, recent theoretical studies on SOR, using a Hubbard U correction to standard DFT calculations, suggested that $\mathrm{O}_{2}{ }^{\bullet-}$ could not be reduced to the peroxide species as a mere consequence of its binding to the active site of SOR. ${ }^{46}$ According to ref 46 , the reduction of $\mathrm{O}_{2}{ }^{\bullet-}$ would occur in a later step, assisted by proton transfer. We thus propose $\mathrm{T} 1$ as a ferrous iron-superoxo species (Scheme 2).

TD-DFT calculations were undertaken in order to investigate if a ferrous iron-superoxo species formed in the active site of SOR could exhibit an absorption band centered around 600 $\mathrm{nm}$, as observed for the T1 intermediate (Figure 1). The model systems were taken from the crystallographic structure of the wt SOR from $D$. baarsii at $1.7 \AA$ resolution. ${ }^{25}$ To build the systems, only the five amino-acids binding iron were taken into consideration, namely H49, H69, H75, H119 and C116. For the ferrous pentacoordinated state (Figure 7a), with iron at a formal oxidation degree of $+\mathrm{II}$, quintet spin state $(\mathrm{S}=2)$ was found to be the most stable, consistently with previous work. ${ }^{46}$ In the optimized structure of the hexacoordinated state (Figure $7 b$ ), superoxide anion is bound to iron via one oxygen atom.
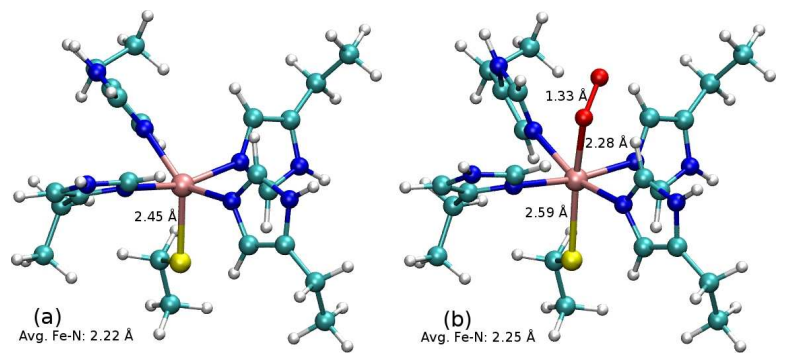

Figure 7. Optimized structures for reduced SOR (a) and reduced SOR with superoxide substrate (b), geometries optimized using the B3LYP/double- $\zeta$ level of theory.

In this second system, quartet and sextet $(S=3 / 2$ and $S=5 / 2)$ structures were found to have very similar energies, as previously reported in ${ }^{46}$. We retained the sextet due to a smaller spin contamination. In the hexacoordinated state, superoxide moiety kept its radical characteristics with a total spin population of 1.05 , consistently with an active site containing an $\mathrm{Fe}^{2+}-\mathrm{OO}^{\bullet}$ electronic arrangement. No $\mathrm{Fe}^{3+}-\mathrm{OO}^{-}$arrangement could be characterized. Finally, twenty transitions were computed by the mean of the TD-DFT formalism (B3LYP/6$\left.311+\mathrm{G}^{* *}\right)$ for both the structures presented in Figure 7 .

The TD-DFT computed spectra are presented in Figure 8. Three transitions have appreciable oscillator strengths for the ferrous pentacoordinated form and four in the case of the superoxide-bound SOR. The oscillator strengths, the orbitals involved and the attribution of charge transfer were summarized in Supporting Information, Table S1. The two spectra showed a similar band around $350 \mathrm{~nm}$ (330 and $370 \mathrm{~nm}$, respectively), attributed to a sulfur to iron charge transfer (Supporting Information Table S1). This is in agreement with ref 47 , where in the case of reduced of $P$. furiosus SOR the bands at 31200 and $33900 \mathrm{~cm}^{-1}$ (295 and $320 \mathrm{~nm}$, respectively) were assigned by MCD spectroscopy to a (Cys) $\mathrm{S}^{-} \rightarrow$ $\mathrm{Fe}^{2+}$ charge transfer. Addition of the superoxide to the penta- coordinated ferrous form led to two new bands at 614 and 475 nm (Figure 8), both attributed to charge transfer to the superoxide ligand. The $614 \mathrm{~nm}$ band could be assigned to a ferrous iron to superoxide charge transfer, while the $475 \mathrm{~nm}$ band would arise from a sulfur to superoxide charge transfer. This latter band occurred between the lone pair of the sulfur and the $\pi^{*}$ orbital located on the superoxide ligand.

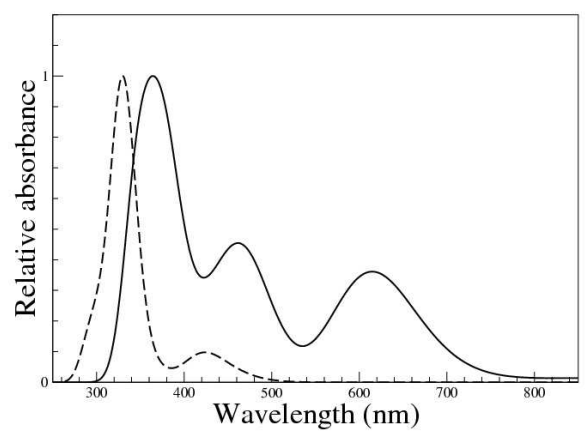

Figure 8. TD-DFT computed UV/Vis spectra for the active site of SOR. Dashed line, pentacoordinated ferrous form (structure a, Figure 7). Solid line, hexacoordinated ferrous form with a $\mathrm{O}_{2}{ }^{\bullet-}$ bound (structure b, Figure 7). Absorbance is given relatively to the highest peak (value of 1 ).

The experimental spectrum of T1 characterized in the 500-700 $\mathrm{nm}$ region (Figure 1), with a broad band centered around 600 $\mathrm{nm}$ fits well with the ferrous iron to $\mathrm{O}_{2}{ }^{\bullet-}$ charge transfer band described by TD-DFT. These data support the proposition of $\mathrm{T} 1$ as a ferrous iron-superoxo species, as shown in Scheme 2.

Whereas iron ferric-superoxo species as reaction intermediates in some non-heme iron containing oxidase-oxygenases have been spectrocopically characterized, ${ }^{48,49}$ to the best of our knowledge, no spectroscopic characterization for a ferrous iron-superoxo species has been reported to date. In the nonheme $\mathrm{Fe}^{2+}$ containing homoprotocatechuate 2,3 dioxygenase, one of the reaction intermediate has been proposed to be a $\mathrm{Fe}^{2+}$ superoxo species, based on X-ray diffraction studies. ${ }^{50}$ This intermediate has been proposed to result from a oneelectron transfer from the substrate chelated to the ferrous iron to $\mathrm{O}_{2}$, hence forming substrate and oxygen radicals, which further recombine, conducing to oxygen insertion into the substrate. ${ }^{51}$ In the case of SOR, the $\mathrm{Fe}^{2+}$ superoxo species, which results from the binding of $\mathrm{O}_{2}{ }^{\bullet-}$ on the ferrous ion, is not expected to prone such oxidation reactions.

\section{CONCLUSIONS}

In this work, we re-investigated the reaction mechanism of the SOR from $D$. baarsii with $\mathrm{O}_{2}{ }^{--}$and focussed on the role of the $\mathrm{K} 48$ residue. We propose a new reaction scheme for the catalytic mechanism (Scheme 2), that redefines both the chemical nature of the first reaction intermediate as an unprecedented ferrous iron superoxo species $\left(\mathrm{Fe}^{2+}-\mathrm{O}-\mathrm{O}^{\bullet}\right)$ and establishes an essential role for $\mathrm{K} 48$ in the control of the evolution of the iron peroxide intermediate to form the reaction product $\mathrm{H}_{2} \mathrm{O}_{2}$. The presence of K48 is shown to be an essential feature to 
avoid the formation of iron-oxo species, which would be otherwise formed in the SOR active site.

SOR catalysis has long been associated with the formation of a ferric iron peroxide intermediate, resulting from an inner sphere reduction mechanism of $\mathrm{O}_{2}{ }^{\circ-}$ by the ferrous iron. The only catalytic competent reaction intermediate (T1) observed by pulse radiolysis was thus proposed to correspond to such an iron hydroperoxide species, which was further protonated to form $\mathrm{H}_{2} \mathrm{O}_{2}$. In fact, one protonation step was observed by pulse radiolysis following the formation of $\mathrm{T} 1$ and appeared to be consistent with such a reaction scheme. ${ }^{18-20}$

Our present results support a reformulation of the chemical nature of the T1 intermediate. We showed that although the K48I mutation had no effect on T1 and on its protonation, it dramatically modified the reaction products, with no production of $\mathrm{H}_{2} \mathrm{O}_{2}$ and formation of a SOR ferrous form instead of a ferric one. In agreement with the recent $\mathrm{X}$-ray structures of the peroxide intermediates trapped in a SOR crystal ${ }^{25}$ and with the evidence that the K48I SOR mutant can form iron-oxo species (see below), our data strongly suggest that $\mathrm{K} 48$ is involved in a second protonation step, that is not observed in pulse radiolysis. This implies that $\mathrm{T} 1$ must be formulated as an unprotonated species, possibly a ferrous iron-superoxo species formed after the fast binding of $\mathrm{O}_{2}{ }^{\bullet-}$ on the ferrous iron. This is in agreement with recent theoretical calculations on SOR, which suggested that the electron transfer from the ferrous iron to $\mathrm{O}_{2}{ }^{\bullet-}$ to form the ferric iron peroxide intermediate is dependent on a further protonation on the $\mathrm{O}_{2}{ }^{\bullet-}$ moiety. ${ }^{46}$ Our TD-DFT calculations fully supported this hypothesis in that the calculations showed that such a ferrous iron superoxo intermediate would present a broad absorption band at 614 $\mathrm{nm}$, which is very similar to the spectrum of $\mathrm{T} 1$ observed by pulse radiolysis. This absorption band was assigned to a ferrous iron to $\mathrm{O}_{2}{ }^{\bullet-}$ charge transfer and, to our knowledge, an absorption band for such an iron species has never been described in the literature. Characterization of a ferrous ironsuperoxo intermediate species is unprecedented in metalloenzymes.

According to our new reaction scheme (Scheme 2), the ferrous iron-superoxo intermediate is protonated by $\mathrm{H}^{+}$from the bulk to form a second reaction intermediate, the ferric iron hydroperoxide species. This second reaction intermediate does not accumulate because, as suggested by the X-ray structure of monomer $\mathrm{D},{ }^{25}$ the hydrogen bond network involving K48 positions a water molecule in close proximity to the proximal oxygen of the iron hydroperoxide, allowing a very fast and $\mathrm{pH}$-independent protonation process to generate $\mathrm{H}_{2} \mathrm{O}_{2}$. Thus, the new proposed reaction mechanism of SOR with $\mathrm{O}_{2}{ }^{\bullet-}$ involves two reaction intermediates, a ferrous iron superoxo and a ferric iron hydroperoxide species (Scheme 2).

In this reaction mechanism, the specificity of the protonation of the iron hydroperoxide intermediate appears to be a key step for the SOR activity. This is illustrated by the fact that the K48I SOR mutant exhibits a new catalytic property, and is able to carry out a $2 \mathrm{e}^{-}$oxidation of olefin in the presence of $\mathrm{H}_{2} \mathrm{O}_{2}$ to form epoxide. These data strongly support the fact that the active site of the K48I SOR mutant forms a high valent iron-oxo species, which is directly responsible for the 2 $\mathrm{e}^{-}$oxidation of olefin. Such formation of a high valent ironoxo species is also fully consistent with the effect of the K48I mutant on the reaction of SOR with $\mathrm{O}_{2}{ }^{--}$, as observed by pulse radiolysis. These data suggest that in the absence of the K48 residue, the iron peroxide intermediate evolves toward a cleavage of its $\mathrm{O}-\mathrm{O}$ bond to form an iron-oxo species. This is in agreement with the absence of a specific protonation of the proximal oxygen in the K48I SOR mutant, as illustrated by the $\mathrm{X}$-ray structure of the iron peroxide intermediates. ${ }^{25}$

Then, these data highlight a pivotal role of K48 in SOR catalysis, which allows for a tight control of the evolution of the iron peroxide intermediate toward the formation of $\mathrm{H}_{2} \mathrm{O}_{2}$.

Though it was proposed that a high-spin state was a determining factor to favour the cleavage of the iron-peroxide $\mathrm{Fe}-\mathrm{O}$ bond to generate $\mathrm{H}_{2} \mathrm{O}_{2},{ }^{44,45}$ our results show that the $\mathrm{O}-\mathrm{O}$ bond cleavage is possible despite the existence of a high-spin iron peroxide intermediate at the non-heme $\left[\mathrm{FeN}_{4} \mathrm{~S}_{1}\right]$ center of SOR.

This work illustrates an example of how an enzyme, SOR, can use reaction intermediate typical of oxygenase enzymes, e.g. iron hydroperoxide species, to carry out antioxidant activity and $\mathrm{O}_{2}^{\bullet-}$ detoxification.

\section{AUTHOR INFORMATION}

\section{Corresponding Author}

Vincent Niviere, Laboratoire de Chimie et Biologie des Métaux, CEA-iRTSV, 17 Avenue des Martyrs, 38054 Grenoble Cedex 9, France. Tel.: 334387891 09; Fax: 334387891 24; E.mail: vniviere@cea.fr

\section{ACKNOWLEDGMENT}

VN and SD acknowledge support from the Agence Nationale de la Recherche, programme Physique et Chimie du Vivant 2008. We thank Adeline Jorge-Robin for assistance in the GC experiments.

\section{ASSOCIATED CONTENT}

\section{Supporting Information}

Relevant transitions by the mean of TD-DFT for the ferrous SOR, penta-coordinated and hexa-coordinated $\left(\mathrm{SOR}_{-} \mathrm{O}_{2}{ }^{--}\right)$structures (Table S1). Complete reference 30. This information is available free of charge via the Internet at http://pubs.acs.org/.

\section{ABBREVIATIONS}

SOR, superoxide reductase; SOD superoxide dismutase; wt, wild-type; GC, gas chromatography; TD-DFT, time-dependent density-functional theory.

\section{REFERENCES}

(1) Imlay, J. A. Ann. Rev. Biochem. 2008, 77, 755-776.

(2) Winterbourn, C. C. Nat. Chem. Biol. 2008, 4, 278-286.

(3) Fridovich, I. Ann. Rev. Biochem. 1995, 64, 97-112.

(4) Jenney, F. E. Jr.; Verhagen, M. F. J. M.; Cui, X.; Adams, M. W. W. Science 1999, 286, 306-309.

(5) Lombard, M.; Fontecave, M.; Touati, D.; Nivière, V. J. Biol. Chem. 2000, 275, 115-121.

(6) Emerson, J. P.; Coulter, E. D.; Phillips, R. S.; Kurtz, D. M. Jr. J. Biol. Chem. 2003, 278, 39662-39668.

(7) Santos-Silva, T.; Trincao, J. ; Carvalho, A. L. ; Bonifacio, C. ; Auchère, F. ; Raleiras, P. ; Moura, I. ; Moura, J. J. G. ; Romao, J. J. Biol. Inorg. Chem. 2006, 11, 548-558.

(8) Grunden, A. M.; Jenney, F. E. Jr.; Ma, K., Ji, M.; Weinberg, M. V.; Adams, M. W. W. Appl. Environ. Microbiol. 2005, 71, 1522-1530.

(9) Kurtz, D. M. Jr. Acc. Chem. Res. 2004, 37, 902-908. 
(10) Pereira, A. S.; Tavares, P.; Folgosa, F.; Almeida, R. M.; Moura, I.; Moura, J. J. G. Eur. J. Inorg. Chem. 2007, 18, 2569-2581.

(11) Pinto, A. F.; Rodrigues, J. V.; Teixeira, M. Biochim. Biophys. Acta 2010, 1804, 285-297.

(12) Nivière, V.; Bonnot, F.; Bourgeois, D. In Handbook of Metalloproteins, Volumes $4 \& 5$, Superoxide reductase, 2011, edited by Albrecht Messerschmidt. Chichester, UK: John Wiley \& Sons, Ltd, pp 246-258.

(13) Yeh, A. P.; Hu, Y.; Jenney, F. E. Jr.; Adams, M. W. W.; Rees, D.C. Biochemistry 2000, 39, 2499-2508.

(14) Coelho, A.; Matias, P.; Fülöp, V.; Thompson, A.; Gonzalez, A.; Carrondo, M. A. J. Biol. Inorg. Chem. 1997, 2, 680-689.

(15) Denisov, I. G.; Makris, T. M.; Sligar, S. G.; Schlichting, I. Chem. Rev. 2005, 105, 2253-2277.

(16) Folgosa, F.; Cordas, C. M.; Santos, J.A.: Pereira, A. S.; Moura, J.

J.; Tavares, P. A.; Moura, I. Biochem. J. 2011, 438, 485-494.

(17) Bonnot, F.; Duval, S.; Lombard, M.; Valton, J.; Houée-Levin, C.; Nivière, V. J. Biol. Inorg. Chem. 2011, 16, 889-896.

(18) Emerson, J. P.; Coulter, E. D.; Cabelli, D. E.; Phillips, R. S.; Kurtz D. M. Jr. Biochemistry 2002, 41, 4348-4357.

(19) Nivière, V.; Asso, M.; Weill, C. O.; Lombard, M.; Guigliarelli, B.; Favaudon, V.; Houée-Levin, C. Biochemistry 2004, 43, 808-818.

(20) Rodrigues, J. V.; Abreu, I. A.; Cabelli, D. E.; Teixeira, M. Biochemistry 2006, 45, 9266-9278.

(21) Bonnot, F.; Houée-Levin, C.; Favaudon, V.; Nivière, V. Biochim. Biophys. Acta 2010, 1804, 762-767.

(22) Mathé, C.; Mattioli, T. A.; Horner, O.; Lombard, M.; Latour, J. M.; Fontecave, M.; Nivière, V. J. Am. Chem. Soc. 2002, 124, 4966-4967.

(23) Mathé, C.; Nivière, V.; Mattioli, T. A. Biophys. Chem. 2006, $119,38-48$.

(24) Mathé, C.; Weill, C. O.; Mattioli, T. A.; Berthomieu, C.; HouéeLevin, C.; Tremey, E.; Nivière, V. J. Biol. Chem. 2007, 282, 2220722216

(25) Katona, G.; Carpentier, P.; Nivière, V.; Amara, P.; Adam, V.; Ohana, J.; Tsanov, N.; Bourgeois, D. Science 2007, 316, 449-453.

(26) Kitagawa, T.; Dey, A.; Lugo-Mas, P.; Benedict, J. B.; Kaminsky,

W.; Solomon, E.; Kovacs, J. A. J. Am. Chem. Soc. 2006, 128, 1444814449

(27) Von Sonntag, C. The Classical Basis of Radiation Biology. Taylor and Francis, London, 1987.

(28) Mottola, H. A.; Simpson, B. E.; Gorin, G. Anal. Chem. 1970, 40, 410-411.

(29) Freccero, M.; Gandolfi, R; Sarzi-Amade, M.; Rastelli, A. J. Org. Chem. 2000, 65, 8948-8959.

(30) Frisch, M. J. et al 2004, Gaussian 03, revision B.05, Gaussian, Inc.: Wallingford, CT.

(31) Becke, A. D. Chem. Phys. 1993, 98, 5648-5652.

(32) Lee, C.; Yang, W.; Parr, R. G. Phys. Rev. B. 1988, 37, 785-789.

(33) Hay, P. J.; Wadt, W. R. J. Chem. Phys. 1985, 82, 270-283.

(34). Bauernschmitt, R.; Ahlrichs, R. Chem. Phys. Lett. 1996, 256, 454-464.

(35) Casida, M. E.; Jamorski, C.; Casida, K. C.; Salhu, D. R. J. Chem. Phys. 1998, 108, 4439-4449.

(36) Cancès, M. T.; Mennucci, B.; Tomasi, J. J. Chem. Phys. 1997, 107, 3210-3221.

(37) As reported for the SOR from D. vulgaris Hildenborough (Huang, V. W.; Emerson, J. P.; Kurtz, D. M. Jr. Biochemistry 2007, 46, 1134211351), the presence of high concentration of formate/formic acid in the pulse radiolysis experiments induced a general acid catalysis on the decay of T1 for the wt, E47A and K48I SORs from D. baarsii, (data not shown). However, in the presence of $10 \mathrm{mM}$ of formate and within the $\mathrm{pH}$ range studied here, this effect was found to be negligible on the $k_{2}$ values determined for the wt, E47A and K48I SORs.

(38) Mathé, C.; Nivière, V.; Mattioli, T. A. J. Am. Chem. Soc. 2005, $127,16436-14441$

(39) Dey, A.; Jenney, F. E. Jr.; Adams, M. W.; Johnson, M. K.; Hodgson, K. O.; Hedman, B.; Solomon, E. I. J. Am. Chem. Soc. 2007, $129,12418-12431$.

(40) Nam, W. Acc. Chem. Res. 2007, 40, 522-531.

(41) Que, L. Jr.; Tolman, W. B. Nature 2008, 455, 333-340.

(42) Kovaleva, E. G.; Lipscomb, J. D. Nature Chemical Biology 2008, 4, 186-193.

(43) Park, M.; Lee, J.; Suh, Y.; Kim, J.; Nam W. J. Am. Chem. Soc. 2006, $128,2630-2634$
(44) Brines, L. M.; Kovacs, J. A. Eur. J. Inorg. Chem. 2007, 1, 29-38.

(45). Bukowski, M. R; Halfen, H. L.; van den Berg, T. A.; Halfen, J. A.; Que L. Jr. Angew. Chem. Int. Ed. 2005, 44, 584-587.

(46) Sit, P. H.-L.; Migliore, A.; Ho, M. H.; Klein, M. L. Journal of Chemical Theory and Computation 2010, 6, 2896-2909.

(47) Clay, M. D.; Jenney, F. E. Jr.; Hagedoorn, P. L.; George, G. N.; Adams, M. W. W.; Johnson, M. K. J. Am. Chem. Soc. 2002, 124, 788805

(48) Mbughuni, M. M.; Chakrabarti, M.; Hayden, J. A.; Bominaar, E. L.; Hendrich, M. P.; Münck, E.; Lipscomb, J. D. Proc. Natl. Acad. Sci. U S A 2010, 107, 16788-16793.

(49) Mukherjee, A.; Cranswick, M. A.; Chakrabarti, M.; Paine, T. K.; Fujisawa, K.; Münck, E.; Que, L. Jr. Inorg. Chem. 2010, 49, 3618-3628.

(50) Kovaleva, E. G.; Lipscomb, J. D. Science 2007, 316, 453-457.

(51) Kovaleva, E. G.; Neibergall, M. B.; Chakrabarty, S.; Lipscomb, J. D. Acc. Chem. Res. 2007, 40, 475-483. 